\title{
Study of pregnancy outcome of threatened abortion and its correlation with risk factors in a tertiary care hospital of Mumbai, India
}

\author{
Dipali S. Sivasane*, Rekha G. Daver
}

Department of Obstetrics and Gynecology, Grant Medical College, Mumbai, Maharashtra, India

Received: 29 August 2018

Accepted: 27 September 2018

\section{*Correspondence:}

Dr. Dipali S. Sivasane,

E-mail: dazzlingdip@gmail.com

Copyright: (C) the author(s), publisher and licensee Medip Academy. This is an open-access article distributed under the terms of the Creative Commons Attribution Non-Commercial License, which permits unrestricted non-commercial use, distribution, and reproduction in any medium, provided the original work is properly cited.

\begin{abstract}
Background: Early pregnancy loss is very common and, in most cases, it can be considered as nature's method to select for a genetically normal offspring. Threatened abortion is a relatively common complication during pregnancy, occurring in approximately $20 \%$ of all pregnancies. Maternal age, Outcome of previous pregnancies, health of mother, any infection etc can be decisive factors in the risk of pregnancy loss.

Methods: The present study was a cross sectional study where patients admitted with threatened abortion were interviewed using pretested semi-structured questionnaire after the treatment. Outcome of pregnancy was recorded. Their basic socio-demographic data along with possible risk factors were recorded. TORCH Ig M and Ig G were done in all patients.

Results: Out of 95 patients admitted with threatened abortion, $42(44 \%)$ patients undergone abortion whereas in 53 $(56 \%)$ patients, pregnancy was continued. Out of total 60 patients admitted with the complain of only vaginal spotting, in 39 pregnancy continued and in 21 patients pregnancy was aborted. (p-value<0.05). 50.52\% were from age group of 21 to 25 years of age. It was also seen that after 35 years of age, significant number of patients aborted. Out of these 11 patients with high BMI, pregnancy was continued only one patient. Out of total 20 patients positive for IgM of toxoplasma infection, pregnancy was aborted in $13(65 \%)$ patients. Out of total 15 patients positive for IgM of cytomegalo virus infection, pregnancy was continued in $11(73.3 \%)$ patients.

Conclusions: Patients of threatened abortion with only symptom of spotting per vagina have good chances of continuation of the pregnancy. Increased maternal age above 35, Overweight and bad obstetric history are also associated with pregnancy loss. Though there was no statistically significant difference it was evident that among all TORCH infections, IgM toxoplasma and Rubella are associated more with pregnancy loss.
\end{abstract}

Keywords: Bad obstetric history, First trimester abortion, Threatened abortion, TORCH

\section{INTRODUCTION}

Early pregnancy loss is very common and, in most cases, it can be considered as nature's method to select for a genetically normal offspring. In fact, it has been accepted that at least $50 \%$ of clinical abortions result from chromosomal abnormalities. ${ }^{1,2}$ The incidence of fetal chromosomal abnormalities is gradually decreasing with duration of pregnancy to less than $1 \%$ among live-born children. By extrapolating this trend toward the time of conception, it can be argued that most pregnancy losses occur at a preclinical stage and that most of them are due to a genetic abnormality. ${ }^{3}$

First trimester abortion is the pregnancy loss in first trimester of pregnancy, before 12 weeks of gestation. Threatened abortion is a relatively common complication during pregnancy, occurring in approximately $20 \%$ of all 
pregnancies. ${ }^{4,5}$ Vaginal bleeding during the first trimester is associated with an approximate $5.5 \%-42.7 \%$ risk for subsequent complete miscarriage. ${ }^{6,7}$

Many authors have observed an increasing risk of fetal death, in particular spontaneous abortion, with increasing maternal age. ${ }^{8,9}$ The association of age of the mother and the increased likelihood of chromosomal abnormalities is manifested by the age-related increase of trisomy 21 and cytogenetic studies on pre-implantation embryos. ${ }^{10}$ Outcome of previous pregnancies is another decisive factor in the risk of pregnancy loss. For young women who have never experienced a loss, the rate of a clinical miscarriage is as low as 5\%. ${ }^{11}$ The risk increases to approximately $30 \%$ for women with three or more losses but with a previous live-born infant and up to $50 \%$ for women without a live-born infant. ${ }^{12,13}$ It is estimated that approximately $33 \%$ of women with so called recurrent miscarriage will have had three consecutive sporadic miscarriages by chance. ${ }^{14}$ High BMI, Anaemia, TORCH infection etc can also be contributing factors for pregnancy loss.

The present study was aimed to study the effect of maternal risk factors on outcome of threatened abortion among the pregnant women admitted with symptoms suggestive of abortion during first trimester of pregnancy.

\section{METHODS}

The present study was a cross sectional study done in a tertiary care hospital of Mumbai among patients admitted in the Gynaecology Department with the symptoms suggestive of threatened abortion in first trimester of pregnancy.

\section{Inclusion criteria}

- Thus, pregnant women with the complain of one or more of the symptoms of abortion like spotting, bleeding, passage of fleshy mass, abdominal pain and passage of grape like substance in first trimester of pregnancy were evaluated and patients diagnosed with threatened abortion were included in the study.

- Thus, study participants were patients diagnosed with threatened abortion and willing to give informed written consent.

Due permission was obtained from Ethical Committee of the institute and also from the hospital to conduct the study. All patients fulfilling the inclusion criteria were included in the study. All patients were explained regarding nature and type of study and after that informed written consent was taken.

\section{Exclusion criteria}

- If patients not agree to give written consent, they were excluded from the study without affecting course of treatment.
Confidentiality of data was maintained at all level of the study.

Once patient was stable from their complains and all emergency treatment given, they were interviewed using pre tested semi-structured questionnaire. All necessary treatment and intervention done with full aseptic precautions. Outcome of pregnancy was recorded. Their basic socio-demographic data along with possible risk factors were recorded in questionnaire. TORCH Ig M and Ig $\mathrm{G}$ were done in all patients.

\section{Statistical analysis}

All data was verified and entered in Microsoft Excel. Data cleaning was done meticulously. Data were analysed using SPSS version 20.

\section{RESULTS}

There were total 95 patients suggestive the symptom of threatened abortion was admitted. Out of these patients, $42(44 \%)$ patients aborted spontaneously whereas in 53 $(56 \%)$ patients, pregnancy was continued.

Table 1: Symptoms and outcome of threatened abortion.

\begin{tabular}{|llll|}
\hline $\begin{array}{l}\text { Symptom } \\
\text { Pregnancy } \\
\text { continued }(\%)\end{array}$ & $\begin{array}{l}\text { Pregnancy } \\
\text { aborted }(\%)\end{array}$ & p-value \\
\hline $\begin{array}{l}\text { Spotting } \\
\text { (per vaginal) }\end{array}$ & $39(73.58)$ & $21(50.0)$ & 0.0089 \\
\hline $\begin{array}{l}\text { Bleeding } \\
\text { (per vaginal) }\end{array}$ & $14(26.41)$ & $20(47.62)$ & 0.0161 \\
\hline $\begin{array}{l}\text { Passage of } \\
\text { fleshy mass }\end{array}$ & 0 & $1(2.38)$ & - \\
\hline Total & $53(100)$ & $42(44.21)$ & \\
\hline
\end{tabular}

Table 1 shows symptom wise distribution of study participants. Out of total 95 patients, 60 (63.15\%) patients were admitted with complain of per vaginal spotting and $34(35.78 \%)$ patients admitted with per vaginal bleeding.

Out of total 60 patients admitted with the complain of only vaginal spotting, in 39 pregnancy continued and in 21 patients pregnancy was aborted. This difference was statistically significant ( $\mathrm{p}$-value $<0.05$ ). Table also shows comparison of symptoms among patients in whom pregnancy continued and patients in whom pregnancy aborted.

It was seen that out of total 53 patients in which pregnancy continued, $39(73.58 \%)$ patients were having complain of spotting whereas only $14(26.41 \%)$ patients were having complain of bleeding.

Similarly, out of total 42 patients of abortion, 21 (50\%) patients were having complain of spotting whereas 20 $(47.62 \%)$ patients were having complain of bleeding. 
Table 2: Maternal age and outcome of threatened abortion.

\begin{tabular}{|c|c|c|c|c|}
\hline Variable & Total & Pregnancy continued (\%) & Pregnancy aborted (\%) & p-value \\
\hline \multicolumn{5}{|l|}{ Maternal age (in years) } \\
\hline$\leq 20$ & 16 & $8(50.0)$ & $8(50.0)$ & \multirow{5}{*}{0.2235} \\
\hline 21 to 25 & 48 & $27(56.25)$ & $21(43.75)$ & \\
\hline 26 to 30 & 17 & $11(64.71)$ & $6(35.29)$ & \\
\hline 31 to 35 & 8 & $6(75.0)$ & $2(25.0)$ & \\
\hline$>35$ & 6 & $1(16.67)$ & $5(83.33)$ & \\
\hline \multicolumn{5}{|l|}{ Gestational age (in weeks) } \\
\hline $4-6$ & 10 & $7(70.0)$ & $3(30.0)$ & \multirow{4}{*}{0.3906} \\
\hline 6- 8 & 31 & $16(51.61)$ & $15(48.39)$ & \\
\hline $8-10$ & 19 & $13(68.42)$ & $6(31.58)$ & \\
\hline $10-12$ & 35 & $17(48.57)$ & $18(51.43)$ & \\
\hline \multicolumn{5}{|l|}{ BMI } \\
\hline Underweight (16.5-18.4) & 0 & 0 & 0 & \multirow{4}{*}{ NA } \\
\hline Normal (18.5-24.9) & 84 & $52(61.90)$ & $32(38.10)$ & \\
\hline Overweight (25.0-29.9) & 6 & $1(16.67)$ & $5(83.33)$ & \\
\hline Obese $(\geq 30)$ & 5 & 0 & $5(100)$ & \\
\hline \multicolumn{5}{|l|}{ Gravidity } \\
\hline G1 & 44 & $24(54.55)$ & $20(45.45)$ & \multirow{4}{*}{0.7180} \\
\hline $\mathrm{G} 2$ & 24 & $14(58.33)$ & $10(41.67)$ & \\
\hline G3 & 19 & $12(63.15)$ & $7(36.85)$ & \\
\hline$\geq \mathrm{G} 4$ & 8 & $6(75.0)$ & $2(25.0)$ & \\
\hline \multicolumn{5}{|c|}{ Previous pregnancy loss (A/ MTP) } \\
\hline NIL & 67 & $37(55.22)$ & $30(44.78)$ & \multirow{5}{*}{0.5655} \\
\hline MTP1 & 3 & $1(33.33)$ & $2(66.67)$ & \\
\hline A1 & 18 & $11(61.11)$ & $7(38.89)$ & \\
\hline $\mathrm{A} 2$ & 5 & $3(60.0)$ & $2(40.0)$ & \\
\hline$\geq \mathrm{A} 3$ & 2 & $1(50.0)$ & $1(50.0)$ & \\
\hline \multicolumn{5}{|l|}{ Anaemia } \\
\hline Mild (8-10) & 20 & $12(60.0)$ & $8(40.0)$ & \multirow{2}{*}{0.6696} \\
\hline Moderate (6-8) & 75 & $41(54.67)$ & $34(45.33)$ & \\
\hline \multicolumn{5}{|l|}{ Bleeding duration (days) } \\
\hline$<5$ & 67 & $37(55.2)$ & $30(44.78)$ & \multirow{3}{*}{0.8776} \\
\hline 5 to 10 & 20 & $11(55.0)$ & $9(45.0)$ & \\
\hline$>10$ & 8 & $4(50.0)$ & $4(50.0)$ & \\
\hline
\end{tabular}

Table 2 shows various maternal factors associated with abortion. Out of total 95 patients of threatened abortion, $48(50.52 \%)$ were from age group of 21 to 25 years of age. It was also seen that up to 35 years of age, number of patients of abortion decreases with age and after 35 years of age, number of patients with abortion were more.

Though, this difference was not statistically significant. Most of the patients were from normal BMI. There were 6 overweight patients and 5 obese patients. Out of these 11 patients, pregnancy was continued only one patient. There were 35 patients with gestational age of 10-12 weeks, 17 patients continued their pregnancy and 18 patients aborted spontaneously.

Out of total 95 patients, 44 patients were first gravida, and out of these 44 patients, pregnancy was continued in 24 patients and aborted in 20 patients. This difference was not statistically significant (p-value $>0.05$ ). It was observed that as the gravidity increases, number of patients with continuation of pregnancy was also increased. Previous abortion was also having effect on outcome of threatened abortion. It was evident that number of patients with abortion increased as the duration of bleeding increased. Though these differences were not statistically significant ( $\mathrm{p}$-value $>0.05$ ).

Table 3: IgM antibody and outcome of threatened abortion (multiple responses).

\begin{tabular}{|llll|}
\hline $\begin{array}{l}\text { IgM } \\
\text { infection }\end{array}$ & $\begin{array}{l}\text { Pregnancy } \\
\text { continued }(\%)\end{array}$ & $\begin{array}{l}\text { Pregnancy } \\
\text { aborted }(\%)\end{array}$ & Total \\
\hline Toxoplasma & $7(35.0)$ & $13(65.0)$ & 20 \\
\hline CMV & $11(73.33)$ & $4(26.67)$ & 15 \\
\hline Rubella & $3(33.33)$ & $6(66.67)$ & 9 \\
\hline HSV & $3(60.0)$ & $2(40.0)$ & 5 \\
\hline
\end{tabular}


Table 3 shows individual TORCH IgM antibody and its association with outcome of pregnancy among patients with threatened abortion. Out of total 20 patients positive for IgM of Toxoplasma infection, pregnancy was aborted in $13(65 \%)$ patients. Out of total 15 patients positive for IgM of Cytomegalo virus infection, pregnancy was continued in $11(73.3 \%)$ patients. Among IgM positive cases Rubella showed worst prognosis with $67 \%$ abortion rate followed by toxoplasmosis $(65 \%)$.

Table 4: IgG antibody and outcome of threatened abortion (multiple responses).

\begin{tabular}{|llll|}
\hline $\begin{array}{l}\text { IgG } \\
\text { infection }\end{array}$ & $\begin{array}{l}\text { Pregnancy } \\
\text { continued }(\%)\end{array}$ & $\begin{array}{l}\text { Pregnancy } \\
\text { aborted }(\%)\end{array}$ & Total \\
\hline Toxoplasma & $12(75.0)$ & $4(25.0)$ & 16 \\
\hline Rubella & $9(45.0)$ & $11(55.0)$ & 20 \\
\hline CMV & $25(54.35)$ & $21(45.65)$ & 46 \\
\hline HSV & $10(83.33)$ & $2(16.67)$ & 12 \\
\hline
\end{tabular}

Table 4 shows individual TORCH IgG antibody and its association with outcome of pregnancy among patients with threatened abortion. Out of total 16 patients positive for IgG of Toxoplasma infection, pregnancy was continued in $12(75 \%)$ patients. Out of total 12 patients positive for $\mathrm{IgG}$ of Herpes Simplex Virus infection, pregnancy was continued in $10(83.3 \%)$ patients. Whereas, out of total 20 patients positive for $\mathrm{IgG}$ of Rubella infection, pregnancy was aborted in $11(55.0 \%)$ patients.

\section{DISCUSSION}

In present study, outcome of total 95 patients threatened abortion were correlated with different factors to study their impact on pregnancy. Out of total 95 patients, 42 (44\%) patients aborted whereas in $53(56 \%)$ patients, pregnancy was continued. The present study shows that bleeding amount and duration are positively related with poor fetal outcome.

In present study, the presence of passage of clot and passage of fleshy mass suggest increased chances of abortion (p:0.02). Also, when spotting group compared with Bleeding group, there was statistically significant (p:0.0010) association found between symptoms and outcome, suggesting increased chance of pregnancy continuation with spotting PV. Gracia CR et al also found that the most common symptom of a miscarriage is bleeding. Of women who seek clinical treatment for bleeding during pregnancy, about half will go on to have a miscarriage. Heavy bleeding is most strongly associated with miscarriage which is matching with present study. Symptoms other than bleeding are not statistically related to miscarriage. Complaint of pain in abdomen is negatively associated with miscarriage. ${ }^{15}$

Also, Viniker DA et al found that the first miscarriage symptom is vaginal bleeding, which can range from spotting to being heavier than a period. A little spotting may be an early sign of miscarriage although fortunately this may amount to no more than a threatened miscarriage and the pregnancy continues, suggesting favorable prognosis of minimal bleeding that is spotting on continuation of pregnancy similar to present study. ${ }^{16}$

Age and success of previous pregnancies are two independent risk factors that affect the loss rate. present study showed that up to 35 years of age, number of patients of abortion decreases with age and after 35 years of age, number of patients with abortion were more. Though, this difference was not statistically significant. Similar finding was observed by Evrenos et al and Lykke JA et al in different studies. ${ }^{17,18}$ The association of age of the mother and the increased likelihood of chromosomal abnormalities is manifested by the age-related increase of trisomy 21 and cytogenetic studies on pre-implantation embryos.

In present study out of total 11 over weight and obese patients, pregnancy was continued only one patient. When maternal Body Mass Index was correlated with outcome of pregnancy, it was found that incidence of abortion was $38 \%$ in patients with normal BMI. But it went on increasing to $83 \%$ in overweight and $100 \%$ in obese patients with increase in BMI. present study suggests significant correlation between BMI and outcome of pregnancy (p:0.0009), increased chances of abortion when BMI is more than normal (overweight, obese). As the BMI increased, incidence of abortion increased. This shows positive correlation of BMI with pregnancy loss.

It was observed that as the gravidity increases, number of patients with continuation of pregnancy was also increased, suggesting successful outcome of previous pregnancy has positive correlation wth pregnancy outcome. On the contrary, Previous pregnancy loss has adverse effect on outcome of threatened abortion. The purported causes of recurrent miscarriage are multiple, ranging from genetic, environmental, infectious, metabolic, and endocrine to purely anatomic ones. The best-defined causes are parental chromosomal abnormalities, metabolic abnormalities, and anatomic abnormalities. It was also seen that number of patients with abortion increased as the duration of bleeding increased. Though these differences were not statistically significant ( $p$-value >0.05). Similar findings were also noted by Hossain $\mathrm{R}$ et al. and Hackney DN et al. ${ }^{19,20}$ Thus, in threatened miscarriage group, these were important for examinations during prenatal care.

When active TORCH infection correlated with outcome of threatened abortion, Rubella showed poor prognosis (66\% abortion rate) followed by toxoplasmosis showing $65 \%$ abortion rate. Comparatively CMV and HSV infection had better outcome with respectively 73 and 60 $\%$ pregnancy continuation rate. Sebastian $\mathrm{D}$ et al observed that toxoplasma $\operatorname{IgM}$ in $50.7 \%$ of the miscarriage cases and this is significant, compared to its 
occurrence in $20 \%$ of the normal. This rate is higher when compared to the $11.6 \%$ Toxoplasma infection observed by Kaur et al in Delhi. ${ }^{21,22}$

Similar to present study, in a study by Sebastian et al it was found that Cytomegalovirus do not have any influence on pregnancy outcome. When patients with threatened abortion were studied for TORCH IgG positive infectionn, it was found that there was no association between $\operatorname{IgG}$ positivity and outcome of pregnancy. As pregnancy continuation rate was higher or almost equal to abortion rate in all cases.

If a patient is identified as being at risk for threatened abortion, the physician has the opportunity to manage the prenatal care differently. Those risk factors that can be controlled can be managed more rigorously and antepartum fetal testing can be started sooner and conducted more frequently. Thus, this study provides a definite evidence for identifying high risk mothers. This study can also be path for larger studies to find out more significant results.

\section{CONCLUSION}

Patients of threatened abortion with only symptom of spotting per vagina have good chances of continue the pregnancy. It was also seen that up to 35 years of age, number of patients of abortion decreases with age and after 35 years of age, number of patients of abortion were more. Though, this difference was not statistically significant. Overweight and bad obstetric history are also associated with increased chances of pregnancy loss in patients diagnosed with threatened abortion. Out of all TORCH infections, IgM toxoplasma and Rubella are associated more with pregnancy loss, though not statistically significant. Whereas TORCH IgG does not affect the pregnancy outcome.

Funding: No funding sources Conflict of interest: None declared

Ethical approval: The study was approved by the Institutional Ethics Committee

\section{REFERENCES}

1. Boué J, Boué A, Lazar P. Retrospective and prospective epidemiological studies of 1500 karyotyped spontaneous human abortions. Teratol. 1975,12:11-26.

2. Hassold T, Chen N, Funkhauser J, Jooss T, Manuel B, Matsuura J, et al. A cytogenetic study of 1000 spontaneous abortions. Ann Hum Genet 1980, 44:151-164.

3. Wilcox AJ, Weinberg CR, O'connor JF, Baird DD, Schlatterer JP, Canfield RE, et al. Incidence of early loss of pregnancy. N Engl J Med. 1988;319:189-94.

4. Farrell $\mathrm{T}$, Owen $\mathrm{P}$. The significance of extrachorionic membrane separation in threatened miscarriage. BJOG. 1996;103(9):926-8.
5. Park IY, Park CH, Lee G, Shin JC. 3432: Prognosis of threatened abortion by embryonic/fetal heart beat rate. Ultrasound Med Biol. 2006;32(5):P264.

6. Chung TKH, Sahota DS, Lau TK, Mongelli JMJ, Spence rJAD, HainesCJ. Threatened abortion: prediction on viability based on signs and symptoms. Aus NZJ Obstet Gynaecol. 1999;39:443-7.

7. Uerpairojkit B, Tannirandorm Y, Manotaya S, Somprasit C, Charoenvidhya D, Wacharaprechanont $\mathrm{T}$, et al. Sonographic findings in clinically diagnosed threatened abortion. J Med Assoc Thai. 2001;84:6615 .

8. Abdalla HI, Burton G, Kirkland A, Johnson MR, Leonard T, Brooks AA, et al. Pregnancy: age, pregnancy and miscarriage: uterine versus ovarian factors. Human Reprod. 1993;8(9):1512-7.

9. Andersen N, Wohlfahrt J, Christens P, Olsen J, Melbye M. Maternal age and fetal loss: population based register linkage study. $\mathrm{Br}$ Med $\mathrm{J}$. 2000;320:1708-12.

10. 10. Munné S, Alikani M, Tomkin G, Grifo J, Cohen J. Embryo morphology, developmental rates and maternal age are correlated with chromosome abnormalities. Fertil Steril. 1995;64:382-91.

11. Regan L, Braude PR, Trembath PL. Influence of post reproductive performance on risk of spontaneous abortion. Br Med J. 1989;299:541-5.

12. Warburton D, Fraser FC. Spontaneous abortion risk in man: data from reproductive histories collected in a medical genetics unit. Am J Hum Genet. 1964;16:1-25.

13. Poland BJ, Miller JR, Jones DC, Trimble BK. Reproductive counselling in patients who had a spontaneous abortion. Am J Obstet Gynecol. 1977;127:685-91.

14. Stenchever MA, Droegemueller W, Herbst AL, Mishell DR. Spontaneous and recurrent abortion. In: Comprehensive Gynecology, $4^{\text {th }}$ ed. St. Louis: Mosby; 2001:280-299.

15. Gracia C, Sammel M, Chittams J, Hummel A, Shaunik A, Barnhart K. Risk factors for spontaneous abortion in early symptomatic first-trimester pregnancies. Obstet Gynecol. 2005;106(5):993-9.

16. Miscarriage symptoms signs, causes \& treatment options, David A Viniker MD FRCOG, Consultant Obstetrician and Gynaecologist at Whipps Cross University Hospital, London - Specialist Interests Reproductive Medicine including Infertility, PCOS, PMS, Menopause and HRT, 2womenshealth.com Abortion mht).

17. Evrenos A, Güngör A, Gülerman C, Cosar E. Obstetric outcomes of patients with abortus imminens in the first trimester. Arch Gynecol Obstet. 2014;289(3):499-504.

18. Lykke JA, Dideriksen KL, Lidegaard O, LanghoffRoos J. First trimester vaginal bleeding and complications later in pregnancy. Obstet Gynecol. 2010;115(5):935-44.

19. Hossain R, Harris T, Lohsoonthorn V, Williams M. Risk of preterm delivery in relation to vaginal 
bleeding in early pregnancy. Eur J Obstet Gynecol Reprod Bio. 2007;135(2):158-63.

20. Hackney DN, Glantz JC. Vaginal bleeding in early pregnancy and preterm birth: systematic review and analysis of heterogeneity. J Maternal-Fetal Neonatal Med. 2011;24(6):778-86.

21. Sebastian D, Zuhara KF, Sekaran K. Influence of TORCH infections in first trimester miscarriage in the Malabar region of Kerala. Afr J Microbiol Res. 2008;2(3):56-9.

22. Kaur R, Gupta N, Nair D, Kakkar M, Mathur MD. Screening for TORCH infections in pregnant women: a report from Delhi. Southeast Asian J Trop Med Public Health. 1999;30(2):284-6.

Cite this article as: Sivasane DS, Daver RG. Study of pregnancy outcome of threatened abortion and its correlation with risk factors in a tertiary care hospital of Mumbai, India. Int J Reprod Contracept Obstet Gynecol 2018;7:4598-603. 